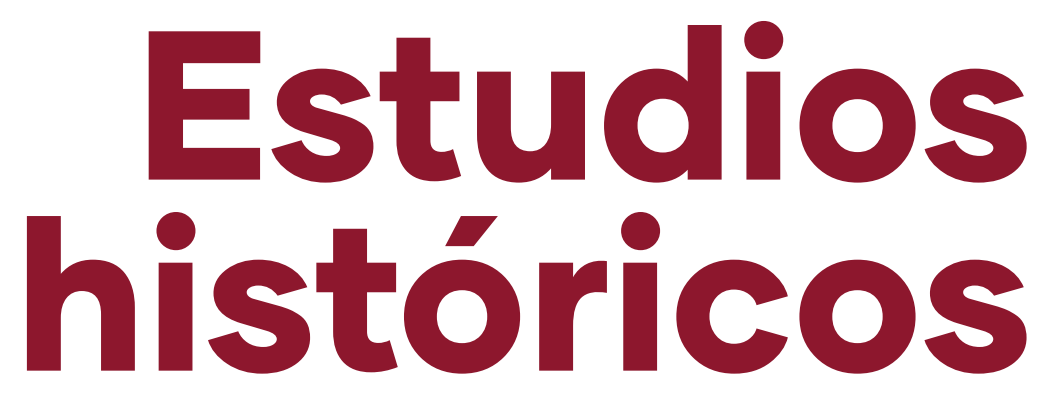

\title{
Anotaciones para una historia de los fenómenos de felicidad en Colombia: segunda mitad del siglo XVIII y principios del XIX
}

\section{Annotations for a history of happiness phenomena in Colombia: second half of the 18th century and early 19th century}

Recibido: 30 de agosto de 2021

Aceptado: 17 de noviembre de 2021

DOI: $10.22517 / 25392662.24912$

pp. 19-43

Yonatan Durán Maturana*

medyco1900@gmail.com https://orcid.org/0000-0002-2053-5243
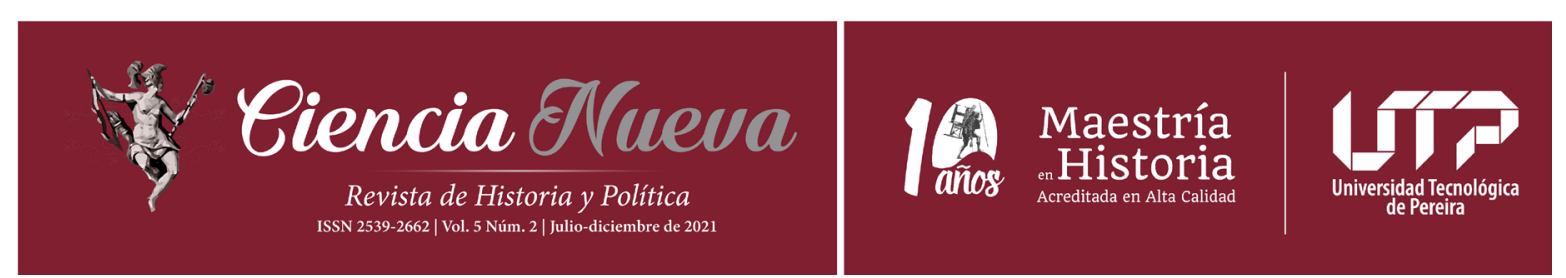

*Historiador por la Universidad de Antioquia, Facultad de Ciencias Sociales y Humanas, Departamento de Historia. El título de su monografía es «La circulación del conocimiento científico a través de la revista médica de Bogotá. Segunda mitad del siglo xix», dirigida por Eduardo Domínguez Gómez.

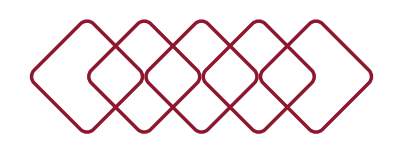




\section{Resumen}

Este trabajo se propone presentar algunos fenómenos de felicidad en la vida social y política del Nuevo Reino de Granada en el contexto de la eclosión que se experimenta en el siglo XVIII el interés público y político por la búsqueda de la felicidad. Para ello, primero se expone el marco interpretativo de partida. Luego, se describe el "complejo anecdótico» considerando algunos fenómenos de felicidad, manteniendo la tesis de que la búsqueda de la felicidad pública surge en capas altas e ilustradas del Antiguo Régimen y se proyecta en círculos concéntricos a través de las organizaciones totalizadoras de la época.

Palabras clave: fenómenos de felicidad, campo de felicidad, felicidad pública, fenómenos políticos de felicidad, fenómenos sociales de felicidad.

\begin{abstract}
This paper aims to analyze some phenomena of happiness in the social and political life of the New Kingdom of Granada in the context of the eighteenth century, when the public and political interest in the pursuit of happiness was growing. In order to do so, the first thing is to present the interpretative framework. Then, the "anecdotal complex" is described, considering some happiness phenomena maintaining the thesis that the pursuit of public happiness arose in the upper, enlightened strata of the Ancien Régime and was projected in concentric circles through the totalizing organizations of the period.
\end{abstract}

Keywords: Phenomena of happiness, field of happiness, public happiness, political phenomena of happiness, social phenomena of happiness.

\section{Introducción}

La felicidad o su conónimo ${ }^{1}$, el bienestar, cuenta como una vasta literatura. Sin embargo, el sentido mundano, vamos a llamarlo así, que se le da a este término se orienta hacia situaciones prácticas que se recortan en el presente inmediato de millones de personas. Si hiciésemos una «lista de lavandería» con las cosas que hacen feliz a la gente, sin duda estarían cosas como viajar, bailar, hacer deportes, meditar, leer libros, y un largo etc. En el fondo está la idea de que la gente feliz busca experiencias antes que posesiones.

Recientemente se publicó The World Happiness Report 2020, que indica el Ranking of Happiness 2017-2019 en el que, por cierto, Colombia ocupa el lugar número cuarenta y cuatro (44), por encima de países como Argentina (55), Ecuador (58), Bolivia (65) y Paraguay (67)2. En consecuencia, existe un uso excesivo de la felicidad en el discurso, no solo político actual, sino científico y periodístico. Y esto aun cuando se trata de una idea indeterminada, inconmensurable, abstracta, extraordinariamente oscura y confusa.

1 Ver Gustavo Bueno, «Conónimos», El Catoblepas, Revista Crítica del Presente, n. ${ }^{\circ} 67$ (2007): 2, http:// www.nodulo.org/ec/2007/n067p02.htm.

2 J. Helliwell, R. Layard y J. Sachs, World Happiness Report 2020 (New York: Sustainable Development Solutions Network, 2020), 20-21. 
¿De dónde proviene esa búsqueda de la felicidad? Más aún, ¿dónde situar la eclosión de fenómenos públicos, por tanto, políticos, de felicidad? El «principio de felicidad» ha sido tratado de diversas maneras en diversas épocas por la filosofía, adquiriendo con cada autor una concepción característica. Como nuestro interés es histórico, delimitado temporal y espacialmente al Nuevo Reino de Granada, nos atenemos a los fenómenos de felicidad en contextos sociales y políticos. Así las cosas, la eclosión de fenómenos de felicidad se da, históricamente hablando, en una época muy reciente: este interés público y político empieza en el siglo XVIII ${ }^{3}$.

En este trabajo se quiere presentar un marco teórico y conceptual que sirva para tratar el problema de la felicidad en la vida social, económica y política de Colombia desde una perspectiva histórica. Por tanto, los casos de fenómenos de felicidad considerados se tratan muy brevemente. En la primera sección se esboza el marco interpretativo y las coordenadas filosóficas. En la segunda sección se describe brevemente el «complejo anecdótico» como fenómenos de felicidad. En la tercera, se describen algunos fenómenos de felicidad en la vida social y política. Habremos llegado así a la cuarta y última sección, en la que proponemos una interpretación de los fenómenos considerados.

Como se verá, esta perspectiva que se propone es distinta a la seguida por Carlos Villamizar Duarte en su obra La Felicidad del Nuevo Reino de Granada. El Lenguaje Patriótico en Santafé (1791-1797). En efecto, el libro de Duarte, siguiendo la perspectiva de la historia conceptual de Reinhart Koselleck y la de Benedict Anderson (Comunidades Imaginadas) gira en torno al concepto de patria y al uso público del lenguaje patriótico que intersecan, sin duda, con algunos contenidos del campo de la felicidad. Así, pues, por un lado, está la patria como mecanismo para construir la «comunidad política imaginada» ${ }^{4}$ y por el otro, el léxico que se le asocia.

Si no interpretamos mal, Duarte se mueve en el estrato conceptual de los fenómenos de felicidad, lo que sucede es que sigue un formalismo metodológico que no entiende el «léxico como un procedimiento operatorio de transformación de los fenómenos en conceptos re-presentados o re-flexivos» ${ }^{5}$. El estudio de Duarte trata más bien de analizar distintas formas de referirse al territorio, teniendo como hilo conductor lo patriótico ${ }^{6}$.

\section{El punto de partida: el campo de la felicidad del materialismo filosófico}

En definitiva, se trata de presentar muy brevemente una estructura conceptual que sirve para explicar los fenómenos de felicidad más allá de su pura descripción positiva. Optamos

3 Para un tratamiento sistemático, lógico, gnoseológico y ontológico de la idea de felicidad, ver: Gustavo Bueno, El mito de la felicidad. Autoayuda para desengaño de quienes buscan ser felices (Barcelona: Ediciones B, 2005). Y para un tratamiento histórico, el libro de Darrin McMahon, Una historia de la felicidad (Madrid: Taurus, 2006).

4 Carlos Vladimir Villamizar Duarte, La felicidad del nuevo reino de Granada: el lenguaje patriótico en Santafé (17911797) (Bogotá: Universidad Externado de Colombia, 2012), 85.

5 Bueno, El mito..., 72.

6 Duarte, La felicidad del nuevo reino de Granada..., 146.

\section{Estudios históricos}


por la perspectiva trazada por el profesor Bueno en su obra ya citada, El mito de la felicidad. Autoayuda para desengaño de quienes buscan ser felices. Partimos, por tanto, de la siguiente tesis: La felicidad es una idea histórica y culturalmente conformada ${ }^{7}$ ¿ Qué significa que la felicidad sea una idea histórica? De pronto, que no se trata de una idea unívoca de felicidad, pues la felicidad está «vinculada a la evolución plural de los distintos grupos humanos».

Ahora bien, el campo de la felicidad que propone el materialismo filosófico se incluye en lo que denomina espacio gnoseológico, en la medida en que la felicidad pueda ser considerada como un campo susceptible de ser trabajado por una o más técnicas o ciencias positivas, o bien, "por disciplinas que, aunque no sean propiamente científicas o técnicas (farmacológicas, gimnásticas, masajísticas, etc.), mantengan o pretendan mantener alguna conexión profunda con determinadas disciplinas científicas» ${ }^{8}$.

7 Aunque existen marcos teóricos e interpretativos alternativos, aquí se opta por el que ofrece el materialismo filosófico de Bueno porque permite tratar el problema de la felicidad en diversas escalas y con herramientas conceptuales que se ajustan mejor al problema histórico de la felicidad. No es un secreto que la tradición filosófica siempre ha tratado el problema de la felicidad. Desde una perspectiva teológica, Aristóteles (por las fuentes, el iniciador de una concepción de la felicidad en sentido filosófico tratada en la Metafísica, xII; en De Anima, III, 7; en su libro x de la Ética a Nicómaco, etc.) y Santo Tomás (la Suma) son lo más importantes.

¿Y en qué se justifica esta elección? En el hecho de que, siendo importantes otras concepciones, no penetran en las cuestiones que la idea de felicidad remueve. Por ejemplo, Gilbert (2006) cree que la felicidad es cualquier cosa que al ser humano se le ocurra hacer; y la reduce a una cuestión de términos, que la gente usa para referirse a las cosas que le gusta. Kanhneman propone la idea de «felicidad objetiva» como experiencia afectiva verdadera que subyace de la evaluación global de la vida; Daniel Kahneman, «Experienced Utility and Objective Happiness: A Moment-Based Approach», en Choices, Values, and Frames, ed. por Daniel Kahneman y Amos Tversky (Nueva York: Cambridge, 2000). En esta misma línea, Alarcón lo define como el «estado afectivo de satisfacción plena que experimenta subjetivamente el individuo en posesión de un bien anhelado»; R. Alarcón, «Desarrollo de una escala factorial para medir la felicidad», Revista Interamericana de Psicología, 40 (2006): 3. Desde otra perspectiva filosófica reciente, Julián Marías nos dice que «La infelicidad en cualquiera de sus formas es algo secundario, derivado, privativo, negativo respeto a la felicidad. Esto nos llevaría a pensar que la felicidad, al menos en algún sentido, pertenece al hombre» Julián Marías, La felicidad humana (Madrid: Alianza Editorial, 1989), 15. Otros, como R. Howell, M. Kern, y S. Lyubomirsky en su artículo Health benefits: meta-analytically determining the impact of well-being on objective health outcomes, se mantienen en una falsa dicotomía (objeto/experiencia) para explicar el problema de la felicidad. Ahora bien, recientemente, a pesar de que no se han realizado muchas investigaciones sobre la felicidad, las que existen se han preocupado más por su medición que por un análisis teórico y conceptual; Emilio Moyano, «Trends and Challenges for the Research of Happiness in Latin America», en Handbook of Happiness Research in Latin America, ed. por Mario Rojas (Dordrecht: Springer, 2016).

8 Bueno, El mito..., 41. El campo de felicidad propuesto por el materialismo filosófico de Bueno moviliza una cantidad de conceptos claves para la explicación del fenómeno de la felicidad, desde diversas perspectivas. De ahí que se haya tomado este como hilo conductor para ofrecer unas líneas generales que sirven para tratar la felicidad en contextos sociales, económicos y políticos que se organiza según tres ejes disociables, pero inseparables, estos son: el «eje sintáctico», «eje semántico» y «eje pragmático»; cada eje consta de tres figuras, el en sintáctico están términos, operaciones y relaciones; en el semántico, las referenciales, fenómenos y esencias; y en el pragmático los autologismos, dialogismos y normas. En la Teoría del Cierre Categorial, para una exposición resumida de la Teoría del Cierre Categorial, ver Gustavo Bueno, ¿Qué es la ciencia? La respuesta de la teoría del cierre categorial (Oviedo: Pentalfa:1995). Para la exposición de los tres ejes con sus figuras, particularmente las páginas 30-41. 
El campo y el espacio de la felicidad intersecan con la ontología a través del campo y el espacio antropológico. El libro que estamos comentado parte del supuesto de que «el campo de la felicidad se circunscribe propiamente en el espacio antropológico $»^{9}$, que está compuesto por tres ejes: eje circular, que se refiere a los contenidos del campo antropológico que a la vez sean inmanentes y personales; eje radial, que se refiere a los contenidos del campo antropológico que sean a la vez trascendentes e impersonales; y eje angular, que se refiere a los contenidos del campo antropológico que sean a la vez trascendentes y personales ${ }^{10}$. «La felicidad es, según esto, una idea, o un conjunto de conceptos, que hay que referir primariamente a la Antropología, y no a la Zoología o a la Teología» ${ }^{11}$.

El campo de la felicidad se estructura en torno a cinco estratos ${ }^{12}$ en los que se agrupan sus diversos elementos. Valga decir, como ya lo hemos insinuado, este campo se dibuja por dos dominios relacionados dialécticamente: el dominio de la felicidad y el dominio de la infelicidad. Así, en el campo de la felicidad no solo aparecerán contenidos felices o gozosos, sino también contenidos infelices o tristes.

Simplificando al máximo, los fenómenos de felicidad, aunque incluyen elementos psicológicos (somáticos o extrasomáticos), se institucionalizan a través de los conceptos; a través de estos, la felicidad se da a escala social, los conceptos hacen que desborde lo puramente subjetual y se convierta en supraindividual, hablaríamos entonces de fenómenos de felicidad institucionalizados (se verá en el «complejo fenoménico» que citaremos más adelante).

«Un campo gnoseológico (científico o paracientífico) es ante todo el territorio en el que tienen lugar las operaciones con conjuntos de términos dados, que mantienen relaciones unos con otros, y que dan lugar a transformaciones (o a construcciones transformativas) de unos términos en otros términos pertenecientes a ese territorio. Transformaciones previamente preparadas por las técnicas, de cualquier tipo que sean (incluyendo aquí a las técnicas mágicas). Y, por extensión, lo que se dice de las ciencias habrá que decirlo de otras disciplinas que mantengan alguna semejanza o parentesco con las ciencias positivas (tales como la Geometría, la Termodinámica o la Genética); y que incluso se autodenominan, o son consideradas en algunas épocas, como ciencias positivas (como ocurre con la Teología dogmática) o incluso con algunas disciplinas filosóficas, aunque su metodología sea muy distinta de la que es propia de las ciencias positivas». Según esto, «Un campo gnoseológico estará siempre inmerso en un espacio gnoseológico, porque ninguna ciencia puede considerarse capaz de agotar su campo, siempre «superficial» (aunque sea el «campo unificado» que buscan los físicos); es decir, porque su campo gnoseológico está limitado, no sólo por la Realidad, sino también por los campos de otras ciencias o de otras disciplinas que no son científicas. Por ello, el espacio gnoseológico contiene también, no sólo las disciplinas precientíficas, sino también las disciplinas antecedentes» [subrayado nuestro]; Bueno, El mito..., 41.

9 Bueno, El mito..., 43: «La idea de un espacio antropológico presupone la tesis de que el hombre sólo existe en el contexto de otras entidades no antropológicas, la tesis según la cual el hombre no es un absoluto no está aislado del mundo, sino que está "rodeado", envuelto, por otras realidades no antropológicas (plantas, animales, piedras, astros)». Para una exposición amplia del espacio antropológico, ver Gustavo Bueno, El sentido de la vida (Pentalfa; Oviedo, 1996); y, del mismo autor, el epílogo de Etnología y Utopía, $2^{\mathrm{a}}$ ed. (Madrid-Gijón: Ediciones Júcar, 1987).

10 Bueno, El mito..., 46.

11 Bueno, El mito..., 43.

12 Por tanto, la estructura general del campo de la felicidad viene dada por sus cinco estratos. El primer estrato corresponde a los fenómenos de felicidad; el segundo estrato a los conceptos de felicidad; el tercer estrato corresponde a las ideas de felicidad; al cuarto a las teorías de la felicidad; y finalmente, el quinto estrato a las doctrinas de felicidad.

\section{Estudios históricos}


Los conceptos de la «constelación felicitaria» son inseparables de los propios fenómenos, en cambio pueden disociarse de ellos: «por ejemplo cuando dos fenómenos son vistos como semejantes, la semejanza entre ellos es ya un concepto y no un fenómeno; estas relaciones de semejanza entre fenómenos son ya conceptos y no constituyen propiamente un fenómeno» ${ }^{13}$. En suma, conceptos y fenómenos se coderteminan. Los fenómenos ya conceptualizados muchas veces van "desbordando" sus orígenes hasta convertirse y referirse a ideas que se relacionan con el campo de la felicidad.

Ahora bien, en esta ocasión nos ocuparemos del primer estrato del campo de la felicidad, los fenómenos de felicidad. El profesor Bueno retoma el sentido helénico del término para evitar la recaída en el idealismo alemán (de Kant o de Husserl): «En su acepción griega, un fenómeno es un contenido del Mundo que se destaca del resto por una cierta rareza o anomalía». El fenómeno, además, «se manifiesta a varios sujetos (o a uno mismo varias veces, y con alguna variación en cada percepción ${ }^{14}$. Esto es: el fenómeno tiene una repetibilidad, lo que hace que sea "correlativo de la esencia o estructura». Según Bueno, el fenómeno en su sentido helénico debe ser corpóreo o, dicho en otras palabras, debe tener un referencial.

En realidad, no hay uno sino varios dominios fenoménicos del campo de la felicidad. Bueno, agrupa estos dominios (felices o infelices) en cuatro rúbricas: 1) aquella que cubre los dominios subjetuales; 2) la que cubre los dominios subjetales de carácter supraindividual, en otras palabras, los grupos sociales; 3) la que cubre los dominios no subjetuales; y 4) la que corresponden a objetos incorpóreos. Para nuestro propósito, nos atenemos a los dominios de la segunda rúbrica, los de carácter supraindividual. Es decir: los fenómenos de felicidad en su «terreno» social y político. Y nuestra elección se hace en virtud de que los dominios fenoménicos supraindividuales asociados a la felicidad son, por lo general, «fenómenos institucionales»: entiéndase «institución» en su sentido antropológico y no puramente político.

\section{Los fenómenos de felicidad como bienestar se dibujan en la historia institucional}

El cuarto rey de Bután, Jigme Singye Wangchuck, al momento de su coronación, en junio de 1974, se pronunció ante el desafío que tenía por delante de gobernar un país al borde de una crisis económica. En ese discurso, Wangchuck decía que «La felicidad interna bruta es mucho más importante que el producto interno bruto» ${ }^{15}$.

En efecto, Bután implementó la felicidad como fundamento de sus políticas de desarrollo, que sería medida con el indicador FIB (Felicidad Interna Bruta). Para el contexto de Bután, ¿cuáles eran las fuentes de esta perspectiva de desarrollo? Una es, sin duda, sus raíces budistas:

13 Bueno, El mito..., 50.

14 Bueno, El mito..., 56.

15 Pablo Guimón, «El reino que quiso medir la felicidad», El País, 29 de noviembre de 2009, acceso el 30 de noviembre de 2021, https:/elpais.com/diario/2009/11/29/eps/1259479614_850215.html 
La felicidad interior bruta se basa en dos principios budistas. Uno es que todas las criaturas vivas persiguen la felicidad. El budismo habla de una felicidad individual. En un plano nacional, corresponde al Gobierno crear un entorno que facilite a los ciudadanos individuales encontrar esa felicidad. El otro es el principio budista del camino intermedio ${ }^{16}$.

El «camino intermedio» significaba, por un lado, situarse en un escenario en el que las características medievales del país se transformaran para convertirse en un país más moderno; por el otro, se trataba de que un país guiado casi exclusivamente por la religión optara por otras vías, diríamos, una tercera vía de desarrollo. El ministro del Interior y de Educación de entonces, Lyonpo Thinley Gyamtso, explicaba muy bien esta situación: «Están los países modernos, y luego está lo que era Bután hasta los años setenta. Medieval, sin carreteras, sin escuelas, con la religión como única guía. Son dos extremos, y la FIB busca el camino intermedio» ${ }^{17}$.

El FIB tuvo sus implicaciones a escala mundial. En la sesión plenaria número 109 de la Asamblea General de la onU se aprobó la resolución «La felicidad: hacia un enfoque holístico del desarrollo», en la que acogía «con beneplácito el ofrecimiento de Bután de convocar un coloquio sobre el tema de la felicidad y el bienestar en su sexagésimo sexto período de sesiones», al tiempo que invitaba a los «Estados Miembros a que emprendan la elaboración de nuevas medidas que reflejen mejor la importancia de la búsqueda de la felicidad y el bienestar en el desarrollo con miras a que guíen sus políticas públicas» ${ }^{18}$.

Apenas pasado un año, mediante acta número 66/281, aprobada en junio de 2012, se proclama en la sesión número 118 el «Día Internacional de la Felicidad» y se exhorta a las naciones miembros a que consideren la felicidad como un objetivo esencial de las políticas públicas. Y reconoce: «La necesidad de que se aplique al crecimiento económico un enfoque más inclusivo, equitativo y equilibrado, que promueva el desarrollo sostenible, la erradicación de la pobreza, la felicidad y el bienestar de todos los pueblos» ${ }^{19}$.

\section{Apuntes sobre la felicidad pública en el siglo XVIII}

Según Hannah Arendt, el manifiesto de los sans coulottes (1793) veía como fin último de la Revolución la felicidad del pueblo antes que la libertad ${ }^{20}$. Según Arendt, la tesis más conocida de «felicidad pública» es acaso la de Joseph Warren, quien la haría depender en 1722 de «una devoción firme y virtuosa a una Constitución libre» ${ }^{21}$.

16 Palabras del lama Mynak Trulku, citadas por Guimón en «El reino que quiso medir la felicidad».

17 Citado por Guimón en «El reino que quiso medir la felicidad».

18 Resolución 65/309, del 19 de julio de 2011, Organización de las Naciones Unidas, 1.

19 Acta número 66/281, de junio de 2012, Organización de las Naciones Unidas, 1.

20 Hannah Arendt, Sobre la revolución (Buenos Aires: Alianza, 2008), 80.

21 Arendt, Sobre la revolución..., 162.

\section{Estudios históricos}


Aquí Arendt está vinculando el sentido de las revoluciones modernas con la idea de libertad, que asocia con la participación en los asuntos públicos, y en este sentido, la revolución no sería otra cosa que la búsqueda de la felicidad pública. Se trata, pues, de una idea de felicidad pública que se opone a la idea de la felicidad del pueblo surgida en la Revolución Francesa, aquella idea que buscaba la mejora de las condiciones materiales del pueblo. A Arendt le preocupaba aquella idea robespieriana de que la virtud significaba la preocupación por el bienestar del pueblo ${ }^{22}$.

En realidad, la génesis moderna de los Estados de Bienestar se encuentra ya en la Declaración de Independencia de los Estados Unidos, redactada por el Congreso el 4 de julio de 1776, que estableció que «la búsqueda de la felicidad es un derecho inalienable de todos los hombres». Decía la Declaración: «Sostenemos por evidentes, por sí mismas, estas verdades: que todos los hombres son creados iguales; que son dotados por su Creador de ciertos derechos inalienables, entre los cuales están la vida, la libertad y la búsqueda de la felicidad...»²3.

La felicidad pública fue tratada por Ludovico Antonio Muratori en su Della Pubblica Felicita: Oggetto De’ Buoni Principi (1749). Desde una perspectiva ilustrada, Muratori propone que los soberanos ilustrados puedan orientar sus políticas hacia la felicidad de sus súbditos. Plantea una distinción fundamental entre felicidad individual y felicidad pública. Dice Muratori en sus comentarios al lector:

Así tambien el deseo maestro y padre de todos los demas que hay en nosotros, es el de nuestro Bien privado, y el de nuestra particular Felicidad. Esto es, nuestro deseo mas ordinario tiene por blanco algun objeto ó medio que pueda redundar poco ó mucho en nuestro Bien. Este no solo es un consejo, sino tambien un impulso incesante de nuestra naturaleza, que se hace sentir tanto del noble como del plebeyo, así de los ignorantes, como de los doctos Hay otro deseo de una esfera mas sublime y de un orígen mas noble, qual es el del Bien de la sociedad, del Bien público, ó de la Pública Felicidad²4.

El primer tipo de felicidad se refiere a una determinación natural humana, mientras que la segunda se determina positivamente. «... siempre es de mucho mérito para con Dios y para con los hombres apetecer y procurar el Bien público como se consiga por medios honestos» ${ }^{25}$. El interés de Muratori por tratar la pública felicidad radica en estas cuestiones:

De aquí ha nacido en mí el deseo y el designio de tratar de la Pública Felicidad, esto es, de aquel bello objeto que debia ser el punto de vista mas agradable de todos los que están destinados por la Providencia á ocupar el Trono, y el blanco de sus continuos pensamientos ${ }^{26}$.

22 Arendt, Sobre la revolución..., 94.

23 United States. Declaration of Independence in Congress, July 4, 1776, a declaration by the representatives of the United States of America, in General Congress assembled (Philadelphia: Printed by John Dunlap, 1776). Disponible en https://lccn.loc.gov/2003576546

24 Ludovico Antonio Muratori, La pública felicidad objeto de los buenos príncipes (España: Imprenta Real, 1790), LXI. La traducción al castellano fue realizada por Pascual Arbuxach, editada en Madrid por la Imprenta Real en 1790.

25 Muratori, La pública felicidad..., LXI-LXII.

26 Muratori, La pública felicidad..., LXII. 
Ahora bien, si no interpretamos mal, Muratori establece dos dominios muy bien delimitados: el de la felicidad y el de la infelicidad. Con respecto al primero nos dice: «Este nombre Felicidad abraza dos ramos muy diversos: el primero consiste en gozar en esta vida muchos bienes, que puedan procurar á el que los posee muchas comodidades: y el segundo en una total esencion de males» ${ }^{27}$. El segundo dominio: «Son ocasiones de infelicidad las varias enfermedades, dolores y daños que pueden desconcertar la buena harmonía de nuestros cuerpos, así como la carestia del preciso alimento, vestido y habitación, de que necesita qualquiera».

Muratori precisa: «nadie se figure que yo entiendo por Pública Felicidad un Estado, bien de Monarquía, ó de República, en quien todos hayan de ser, ó puedan llamarse felices». Y enfatiza con un principio de realidad: «No hay Gobierno que pueda arrancar de la mayor parte del pueblo las congojas de la pobreza, ni los dolores y gravámenes de las varias enfermedades $»^{28}$.

En suma, entiende por felicidad pública «no otra cosa que la paz y sosiego que un Principe ó Ministro sabio y amante del bien, procura á su pueblo en quanto le sea posible, previniendo y alejando de él los desórdenes que teme, y remediando los sucedidos». Esto es posible "por medio de una puntual y exacta justicia: cobrando tan discretamente los tributos, que se contente con el vellon de su rebaño, sin arrancarle la piel y despojarle de ella», y sobre todo, "proporcionando al pueblo toda la comodidad, ventajas, y bien que le sea dable» ${ }^{29}$.

En cuanto a la política social, nos ofrece más que un cambio estructural, reformas o modificaciones: reducir la miseria de la población urbana y rural. La felicidad pública implicaba una política ilustrada, una economía regulada en función del bienestar colectivo y unos principios religiosos. En términos estrictamente económicos, proponía, por citar algunos casos: 1) liberación de las mercancías de las excesivas cargas aduaneras, 2) una política fiscal más repartida entre los súbditos nobles y eclesiásticos y que no gravara a los campesinos, 3) la supresión de las limitaciones a la posibilidad de venta de la tierra, dispuesta en la ley toscana sobre el fedecommesso y la manomorta.

\section{Fenómenos de felicidad en la segunda mitad del siglo XVIII y principios del XIX}

Ahora bien, para el contexto que nos ocupa es imposible separar la felicidad de su trasfondo económico y político. Este fenómeno se dibuja en una relación de dos términos importantísimos: la riqueza y la pobreza. Como vimos, estos términos se pueden reinterpretar dialécticamente como dos dominios (felicidad e infelicidad) del campo de la felicidad. En 1781, Gaspar Melchor de Jovellanos al dirigirse a la Real Sociedad de Amigos del País de Asturias, definía la felicidad en los siguientes términos:

27 Muratori, La pública felicidad..., 1

28 Muratori, La pública felicidad..., 5

29 Muratori, La pública felicidad..., 6

\section{Estudios históricos}


Entiendo aquí por felicidad aquel estado de abundancia y comodidades que debe procurar todo buen gobierno a sus individuos. En este sentido, la provincia más rica será la más feliz, porque en la riqueza están cifradas todas las ventajas políticas de un estado. Así pues, el primer objeto de nuestra Sociedad debe ser la mayor riqueza posible del Principado de Asturias ${ }^{30}$.

Esto es de una importante significación. El sentido que Jovellanos le da al término felicidad desborda sus contornos estrictamente morales tradicionales que, por cierto, algunos todavía seguían presentes en la felicidad pública de Muratori. Pareciera que Jovellanos está «liberándola» del sentido benéfico que se le había atribuido a la pobreza, benéfico por cuanto la pobreza ubicaba a las personas en una situación de privilegio con respecto a Dios ${ }^{31}$.

En una palabra, a lo que se asiste aquí es a un desbloqueo, si vale hablar así, de la reflexión económica con respecto a la moral cristiana. Según nos recuerda Marc Marti, también Campomanes asociaba la riqueza con la felicidad y con su situación demográfica: «La felicidad más grande de una república consiste en que esté muy poblada, pues la población abundante es la más grande riqueza que pueda desear un pueblo» ${ }^{32}$.

Décadas antes al «Discurso económico» de De Jovellanos, el concepto de felicidad tenía dos sentidos, propios del siglo XVIII, la felicidad temporal y la felicidad eterna: de la dialéctica de ambos se va dando una extensión de la felicidad temporal hasta envolver al sentido económico y hacer cada vez más borroso el sentido de la felicidad eterna; extensión que es el producto de la secularización surgida a raíz de la Ilustración.

En Hispanoamérica, este proceso se puede observar muy bien en 1768, cuando Francisco Antonio Lorenzana, arzobispo de México, publica sus Reglas para que los naturales de estos Reynos sean felices en lo espiritual, y temporal. El caso de Lorenzana es un buen ejemplo de la fenomenología de felicidad pública, de fenómenos de felicidad como bienestar en el siglo XVIII. Dice Lorenzana:

Que los Naturales trabajen, y tengan las mugeres sus Telares para fabricar la ropa, que ellos, y sus hijos gastan, y nunca anden desnudos, ni sucios, porque se pierde el pudor, y la salud, y se mueren muchos niños por falta de aseo, y limpieza, matándoles la hediondez... (subrayado nuestro) ${ }^{33}$.

30 Gaspar Melchor de Jovellanos, «Discurso económico sobre los medios de promover la felicidad de Asturias, dirigido a su Real Sociedad», Biblioteca Virtual del Principado de Asturias, https://bibliotecavirtual.asturias.es/ i18n/consulta/registro.cmd?id=505

31 Jacques Soubeyroux, «El discurso de la Ilustración sobre la pobreza. Análisis de una formación discursiva», Nueva Revista de Filología Hispánica 33, n. ${ }^{\circ} 1$ (1984):115-132.

32 Citado en Marc Marti, «El concepto de felicidad en el discurso económico de la Ilustración», Cuadernos Dieciochistas 13 (2013): 258.

33 Francisco Antonio Lorenzana, Reglas para que los naturales de estos Reynos sean felices en lo espiritual, y temporal, en Cartas pastorales y edictos del señor D. Francisco Antonio Lorenzana y Buitron, Arzobispo de Mexico, ed. por Iglesia Católica. Arquidiócesis de México (México: Imprenta del Superior Gobierno, del Sr. D. Joseph Antonio de Hogal, 1770), 45-49. Versión en línea en http://cdigital.dgb.uanl.mx/ la/1080044716/1080044716.html. 
Y en la nota a esa regla nos describe con abundantes datos, fenómenos de felicidad en la vida social:

Que tengan Escuela de Castellano, y aprendan los niños á leer; y escribir, de este modo adelantará, sabran cuidar su casa, podrán ser Oficiales de República, y explicarse con sus Superiores, ennobleciendo su Nácion, y desterrando la ignorancia, que tienen, no solo de los Mysterios de la Fe, sino también del modo de cultivar sus tierras, cria de ganados, y comercio de sus frutos, á lo que fe añade ser falta de respeto hablar en fu Idioma con los Superiores, ó delante de ellos, pudiendo hacerlo en Castellano, aunque sea hablando poco. (subrayado nuestro) ${ }^{34}$.

El sentido que le da De Jovellanos y antes Lorenzana a la felicidad es el mismo que se describe en el Nuevo Reino de Granada. Y esto no es casualidad. Una de las principales razones es acaso las reformas borbónicas: uno de los mecanismos por los cuales el discurso de la felicidad pública llega, por extensión, a través de su estructura político-administrativa (funcionarios visitadores, burócratas, oficiales reales, etc.), a Hispanoamérica.

\section{Fenómenos de felicidad en la vida social y económica}

Los fenómenos sociales, por tanto, supraindividuales, asociados a la felicidad, se dan a través de instituciones sociales o culturales, que orienten los contenidos de felicidad en ciertas direcciones. Como veremos, para el contexto que estamos estudiando esos fenómenos eran orientados, o pretendían orientarse, por una institución del Antiguo Régimen de suma importancia, las Reformas Borbónicas.

En efecto, las innovaciones en la administración del Nuevo Reino de Granada se introdujeron a través de la figura del visitador regente, figura del reformismo borbónico ${ }^{35}$. Para

34 Lorenzana, Reglas..., 1-2.

35 Aunque el alcance del reformismo borbón para en el Antiguo Régimen suscita todavía hoy diversas interpretaciones y, por tanto, no constituye consenso en los modelos explicativos. Por ejemplo, dice Luis Navarro García que el «reformismo borbónico en relación con las Indias, aunque preparado por toda una cadena de disposiciones a lo largo de más de medio siglo, tuvo su fase culminante, como proyecto político asumido por el Gobierno, entre 1763 y 1772». Luis Navarro García, «La crisis del reformismo borbónico bajo Carlos IV», Temas Americanistas 13 (1997), 2. Aquí Navarro García está reconociendo que un proyecto de tal magnitud no es posible que haya surgido espontáneamente a cargo de un hombre, sino que es el resultado de concatenaciones precedentes de muchos años atrás, pero que es justo en el periodo que va de 1763 a 1787, donde se da la aplicación, bajo la figura de Carlos III, en Hispanoamérica. Por su parte, coincidiendo con Navarro García en cuanto a que antes del Gobierno de Carlos III las reformas borbónicas tuvieron alguna aplicación en Hispanoamérica, Adrian J. Pearce argumenta que los cambios e innovaciones más importantes fueron introducidos en los primeros años de la dominación borbónica, es decir, 1720-1750; Adrian J. Pearce, The origins of Bourbon reform in Spanish South America, 1700-1763 (New York: Palgrave McMillan, 2010). De ahí que muchos autores, como Eissa-Barroso y Vásquez, digan que las primeras épocas de borbónicas son una edad olvidada; F. Eissa-Barroso y A. Vásquez, Early Bourbon Spanish America. Politics and Society in a Forgotten Era (1700-1759) (Bostón:

\section{Estudios históricos}


ese cargo en el Nuevo Reino fue designado, en 1778, Juan Francisco Gutiérrez de Piñeres. Su propósito era hacer una revisión del estado del gobierno: principalmente lo concerniente a las rentas, el sistema de recaudo y administración fiscal ${ }^{36}$.

Y parece que, en cuanto a lo que nos ocupa, Piñeres hacía bien la tarea. El Virrey Caballero y Góngora declaraba que, bajo la administración del Virrey Manuel Antonio Flórez Maldonado, gobernante durante el tiempo en el que el visitador general aplicó una serie de reformas, «la administración virreinal estaba alcanzando la felicidad»:

La Real Hacienda, abandonada hasta sus días a las codiciosas manos de los arrendadores, tomó mejor aspecto y notable incremente, dándole nueva planta y sucesivamente puso en administración y formó instrucciones para la renta de Tabacos conforme estaba mandado por Su Majestad, practicando lo mismo con las de aguardientes y Alcabalas. Tan de raíz tomó el fomento de las rentas reales en un país en que los habitantes son pobres y ociosos y las atenciones del erario mucho mayores que su ingreso ${ }^{37}$.

\section{Según Caballero y Góngora:}

...de este modo todo prosperaba en sus manos y en todo se veía una feliz resolución. La Real Hacienda se engrosaba; el comercio se extendía; las rudas artes mejoraban; la agricultura se fomentaba; las provincias se comunicaban; los cuerpos militares se arreglaban; todo anunciaba una próxima felicidad ${ }^{38}$.

En materia educativa también las cosas, al menos intencionalmente, pretendían cambiar. Sírvanos como ejemplo la planeación de una nueva universidad pública que el Virrey Manuel Guirior encomendó, en 1774, a Francisco Antonio Moreno y Escandón ${ }^{39}$.

Brill Academic Publisher, 2013). Para una revisión pormenorizada en torno a la cuestión borbónica en Hispanoamérica, ver Di Falco, A. «El reformismo borbónico en España y en las colonias americanas: un recorrido historiográfico», Cultura Latinoamericana 27, n. ${ }^{\circ} 1$ (2018): 242-272.

36 Ver Margarita Garrido, Reclamos y representaciones. Variaciones sobre la política en el Nuevo Reino de Granada 1770-1815 (Bogotá, Banco de la República, 1993). Jaime Jaramillo, «La administración colonial», Nueva Historia de Colombia (Editorial Planeta, 1989), 183-86.

37 Antonio Caballero y Góngora, «Relación del estado del Nuevo Reino de Granada, que hace el arzobispo obispo de Córdoba a su sucesor el excmo. Sr. D. Francisco Gil y Lemos. Año de 1789», en Relaciones e informes de los gobernantes de la Nueva Granada, editado por Germán Colmenares (Bogotá: Biblioteca Banco Popular, 1989), 364-365.

38 Antonio Caballero y Góngora, «Relación del estado del Nuevo Reino de Granada, que hace el arzobispo obispo de Córdoba a su sucesor el excmo. Sr. D. Francisco Gil y Lemos. Año de 1789», 365.

39 Jaime Jaramillo, «El proceso de la educación en el virreinato», Nueva Historia de Colombia (Bogotá: Editorial Planeta, 1989), 207-14. Según nos cuentan Javier Ocampo López y Consuelo Soler (2012), la primera reforma educativa estuvo a cargo del virrey Manuel Guirior, «quien auspició en 1774 el plan de estudios para la educación en el Nuevo Reino de Granada, plan que sería redactado, en efecto, por el fiscal de la Real Audiencia, Francisco Moreno y Escandón. Esto implicó que la educación fuese considerada como una función del Estado, donde se defendía el espíritu educativo». «El plan de estudios del fiscal Moreno y Escandón fue obligatorio exclusivamente para Santafé de Bogotá, la capital del Nuevo Reino de Granada y, en especial, para la educa- 
Vamos ahora a la provincia de Antioquia por boca de su visitador Francisco Silvestre. En su Relación de la provincia de Antioquia nos dice:

Un reino en lo político no es otra cosa, que una familia más numerosa. La misma abundancia de ella, o sus Individuos exige orden y más extensivas reglas; pero acomodadas a sus circunstancias locales. Sin aquél y éstas nada puede prosperar ni adquirir progresos. Quien las debe fomentar, y establecer es el padre de familias. Es decir el rey a quien Dios ha cargado con este peso sin otra recompensa, que la gloria de hacer felices a otros, y llenar de este modo el papel que le ha repartido en el mundo para que viva eternamente en el otro ${ }^{40}$.

Silvestre exhortaba al monarca, encargado de la felicidad de sus súbditos, a conducir felizmente la embarcación hacia el puerto: «... por lo mismo del primer impulso del Monarca, que es la atalaya, o el piloto, que debe estar alerta y velar sobre todos para conducir felizmente la embarcación al puerto, es que debe resultar o no el acierto» ${ }^{41}$.

En 1803, un tal Antonio de las Carreras y Pauquet, vecino de la provincia de Pasto y residente en Madrid, envió una carta a Pedro Ceballos, secretario del despacho universal de Estado, en la que manifestaba que asuntos importantes al Estado en todas sus relaciones lo habían conducido desde el Nuevo Reino de Granada a España. Según Carreras y Pauquet, en 1791, había enviado unos documentos desde el Reino donde describía su viaje por la provincia de Pasto en Popayán, y ofrecía planes de felicidad pública. No hemos podido encontrar esas cartas que Carreras y Pauquet envió en $1791^{42}$.

Un ejemplo más. Se trata de Juan Antonio Mon y Velarde, (que se desempeñó como gobernador durante el tiempo que Francisco Silvestre estaba en Santafé con asuntos legales), nombrado visitador general de la provincia de Antioquia en $1784^{43}$. Mon y Velarde tenía el mismo propósito que los visitadores precedentes de acuerdo con el "plan reformador». Los puntos más interesantes del proyecto de este visitador se pueden enumerar de la siguiente ma-

ción superior: el Colegio Mayor del Rosario y el Colegio Mayor de San Bartolomé»; Javier Ocampo López y Consuelo Soler Lizarazo. Reformismo en la educación colombiana. Historia de las políticas educativas 17701840 (Bogotá: Instituto para la Investigación Educativa y el Desarrollo Pedagógico-IDEP, 2012), 15. Pero este plan, en cierto sentido, ilustrado, de Moreno y Escandón, no duró más de cinco años, de 1774 a 1779. Para más sobre este interesante hecho histórico, ver: Teresa Houghton, La Ilustración en Colombia. Bogotá: Universidad Santo Tomás, Biblioteca Colombiana de Filosofía, 1990; Antonio Cacua Prada, Historia de la Educación en Colombia (Bogotá: Academia Colombiana de Historia, 1997). Desde otra perspectiva, desde la vida cotidiana, Renan Silva en su obra Los ilustrados de Nueva Granada 1760-1808 nos ofrece un análisis de los mecanismos mediante los cuales circulaban y se difundían aspectos de la Ilustración, que tiene que ver mucho con la reorganización de la administración en la época que estamos estudiando.

40 David James Robinson, Francisco Silvestre. Relación de la provincia de Antioquia (Medellín: Secretaría de Educación y Cultura de Antioquia, 1988), 21-23

41 Robinson, Francisco Silvestre..., 23.

42 Archivo General de Indias, ES.41091.AGI/23//ESTADO,57, N.28. Disponible en el Portal de Archivos Españoles (PARES).

43 Emilio Robledo, Bosquejo biográfico del señor oidor Juan Antonio Mon y Velarde. Visitador de Antioquia, 1785-1788 (Bogotá: Banco de la República, 1954), 58.

\section{Estudios históricos}


nera: 1) aumento de la población; 2) creación de nuevos asentamientos, 3) diversificación de los cultivos; 4) mejora de vías de comunicación; 5) reducción de la vagancia y la mendicidad; 6) organización de la actividad minera y comercial:

En procurar cuanto sea conducente al mayor beneficio de estos habitantes y desempeño de mi comisión, he procurado con la mayor reflexión, aplicarme a conocer aquellos asuntos que exigen más pronto remedio: tomar todas aquellas noticias que sean interesantes para el mejor régimen y arreglo de las materias en que interesa la religión, el estado, la causa pública, y por forzosa consecuencia, la del $\operatorname{particular}^{44}$.

Según su diagnóstico, en la provincia de Antioquia no se reconocía la industria y todo se introducía de afuera a enormes costos, «apenas se conoce artesano que viva de su oficio, pues unos más y otros menos, todos procuran sembrar para ayudar de su manutención». Y agrega: «De las cuatro partes de la provincia, se puede asegurar sin temeridad que las dos y media y aun las tres se hallan incultas y casi despobladas».

Finalmente, su sorpresa ante la razón de la infelicidad de los súbditos es muy reveladora: «las comunes contiendas que ocurren son de tierras y no sobrando otra cosa según lo expuesto, parece como paradoja el asentar que por falta de tierras se hallan reducidos estos habitantes al más infeliz estado» ${ }^{45}$.

Ahora bien, del diagnóstico Mon y Velarde se sigue que la infelicidad se recortaba en la vida económica de la provincia; era causada, precisamente, por la falta de incentivos al comercio interno, poco trabajo artesanal, la poca diversificación de cultivos y poco aprovechamiento de las tierras. Entonces ¿cómo lograr la transformación de estado de infelicidad en estado de felicidad?

Según Bueno, el criterio para clasificar los términos que hacen parte del campo de la felicidad es aquel que tiene que ver con «la distinción entre los conceptos técnicos (es decir, los conceptos vinculados a una operación técnica de transformación, mantenida en la inmanencia del campo, en el sentido dicho) y las ideas que "envuelven" desde fuera a esos conceptos técnicos» ${ }^{46}$. Estas operaciones de transformación pueden consistir:

1) bien en transformaciones de estados de infelicidad temporal en estados de felicidad (por ejemplo, transformación de estado de dolor, de enfermedad, de hambre, en estados de tranquilidad, de salud o de bienestar); 2) o bien en transformaciones de estados de felicidad corporal en otros estados de felicidad, bien sea a título de mero mantenimiento (transformaciones idénticas), bien sea a título de una disposición feliz, por otra equivalente o por otra considerada como mejor ${ }^{47}$.

Mon y Velarde nos ofrece una prueba de ello con su «plan reformador». La operación técnica

44 Emilio Robledo, Bosquejo biográfico..., 68.

45 Emilio Robledo, Bosquejo biográfico..., 73.

46 Bueno, El mito..., 111.

47 Bueno, El mito..., 111. 
de transformación de los estados de infelicidad en felicidad implicaba fomentar el comercio y la agricultura y aprovechar la mayor cantidad de tierras mediante su población y su cultivo. Para Mon y Velarde:

Siendo la comisión que el excelentísimo Virrey se ha designado poner a mi cuidado principalmente dirigida a beneficio de todos sus súbditos, habitantes y existentes en esta provincia, para que haciéndose útiles a sí mismos puedan contribuir con más facilidad a su augusto y piadoso soberano que tan liberalmente la dispensa sus gracias, y procura sus alivios; me ha parecido conveniente dar una idea de los principales objetos que comprende, para que conocidas sus ventajas, se esmeren todos en proponer y proporcionar los medios y servicios que los hagan asequibles, con menos gravamen de lo público y de los particulares, y debiendo los ilustres cabildos, sus nobles individuos ser los primeros y que más se señalen en su logro ${ }^{48}$.

Nos movemos ahora en los límites de los fenómenos de felicidad pública:

...concurran todos con sus luces, experiencias y conocimientos a tan loable empresa, debiendo todos disfrutar de sus efectos y participar del honor que es debido a cualquiera que promueve el interés de su rey y la felicidad de su república ${ }^{49}$.

En las «ordenanzas que debe observar el ilustre cabildo de la Villa de Medellín para su gobierno económico y directivo» se lee esto: «Pueden y deben los cabildos, como que representan todo el pueblo y se consideran padres de la república, promover todo lo que sea bien y felicidad de sus habitantes ${ }^{50}$. Como puede verse, tanto en su momento social como en el económico, estas transformaciones se mantienen en la inmanencia del campo ${ }^{51}$.

Por otra parte, habíamos dicho que los dominios fenoménicos supraindividuales asociados a la felicidad son en su mayoría «fenómenos institucionales»: instituciones sociales o culturales que, por la razón que fuera, han llegado a centrarse en torno a alguno de los contenidos que forman parte del campo de la felicidad.

Otro procedimiento de transformación de los estados de infelicidad en felicidad se observa el problema de la pobreza y mendicidad. Este problema obtuvo un tratamiento especial de parte de las autoridades. Para el virrey Pedro Mendinueta y Múzquiz era necesario compadecerse del pobre a través de la caridad cristiana, así lo deja ver en su Relación de Mando. Su diagnóstico era más o menos este: la mendicidad y la ociosidad eran producto de la falta de aplicación al trabajo, de educación, la ineficacia normativa ${ }^{52}$.

48 Robledo, Bosquejo biográfico..., vol. II, 372-73

49 Robledo, Bosquejo biográfico..., vol. II, 373.

50 Archivo General de la Nación (AGN), Cabildos SC7, 1, D10, f. 10

51 Bueno, El mito..., 111: «Siempre que las transformaciones se mantengan en la inmanencia del campo constituido por los sujetos corpóreos así definidos, suponemos que nos mantendremos también en el ámbito de los conceptos técnicos».

52 Pedro Mendinueta, «Relación del estado del Nuevo Reino de Granada, presentado por el Excmo. Sr. Virrey D. Pedro Mendinueta», en Germán Colmenares, Relaciones e informes de los gobernantes de la Nueva Granada, vol. II (Bogotá: Biblioteca Banco Popular, 1989), 72.

\section{Estudios históricos}


La transformación consistía en la rehabilitación, en someterlos a un proceso de educación en nuevas formas de civilidad y enseñarles un oficio para que engrandecieran al Reino ${ }^{53}$. En efecto, esta transformación implicó la construcción de instituciones: hospicios, casas de recogidas, niños expósitos, etc. Es el caso del Hospicio de Santafé, creado a finales del siglo xVIII, que enseñaba la fabricación de tejidos a los moradores ${ }^{54}$. La creación de otras instituciones como los hospitales ${ }^{55} \mathrm{y}$ las universidades también hacen parte de estas operaciones de transformaciones de las que venimos ${ }^{56}$.

\section{Fenómenos de felicidad en la vida política}

Las fuentes más ricas para estudiar los fenómenos de felicidad en la vida política son sin duda las constituciones. Con esto no se quiere decir que este «sector» del campo de felicidad se agote en estas fuentes; más bien que son de una riqueza extraordinaria, ponderan el sector. Es evidente que a través de estas fuentes la felicidad se libera de su determinación estrictamente subjetivista, sin perjuicio de que como es natural desde el dominio intersubjetivo, esto es, social, se proyecte hacia el individuo. Citemos algunos casos.

Así, la felicidad no solo aparecerá en las grandes declaraciones que se han hecho: Declaración de Derechos de Virginia (junio, 1776), Declaración de Independencia de los Estados Unidos (julio, 1776), Declaración de Derechos del Hombre y del Ciudadano (1789), sino que se «refleja» en las diversas constituciones que empiezan a surgir a finales del siglo XviII (por ejemplo, la Constitución francesa de 1791 y la de 1793) y durante el siglo xIx.

Para Colombia, esto lo podemos ver desde muy temprana su andadura, así sea intencional, como Nación política. El Acta de Independencia de Nueva Granada (julio de 1810) dice:

Juramos por el Dios que existe en el Cielo, cuya imagen está presente y cuyas sagradas y adorables máximas contiene este libro, cumplir religiosamente la Constitución y voluntad del pueblo expresada en esta acta [...] conservar la libertad e independencia de este Reino en los términos acordados; trabajar con infatigable celo para formar la Constitución bajo los puntos acordados, y en una palabra, cuanto conduzca a la felicidad de la Patria ${ }^{57}$.

53 Pedro Mendinueta, «Relación del estado del Nuevo Reino de Granada», 74.

54 Julián Vargas Lesmes, La sociedad de Santafé colonial (Bogotá: CINEP, 1990), 294.

55 Ver Adriana María Alzate Echeverri, «Lugares de espanto y refugio: aspectos de la vida de algunos hospitales del Nuevo Reino de Granada, 1750-1810», en Imperios ibéricos en comarcas americanas. Estudios regionales de historia colonial brasilera y neogranadina (Bogotá: Universidad del Rosario, 2008), 15.

56 Las ordenanzas formadas para el gobierno y arreglo del muy ilustre Cabildo de la Ciudad de Antioquia, donde se explica la obligación de cada uno de sus individuos, formadas por Mon y Velarde, son una fuente rica para analizar estas cuestiones. En general, el Fondo de Cabildos (1550-1818), disponible en el Archivo General de la Nación de Colombia. AGN, Cabildos SC7,1 al SC.7,11.

57 Acta de Independencia de Nueva Granada, 20 de julio de 1810. Subrayado nuestro. Fragmento tomado de Enrique Ortega Ricaurte, Cabildos de Santafé de Bogotá: cabeza Nuevo Reino de Granada, 1538-1810 (Bogotá: Imprenta Nacional de Publicaciones, 1957), 285. 
Un año más tarde, en la primera Constitución política, la Constitución de Cundinamarca (1811), se vuelve a incidir, desde el preámbulo, en la felicidad. Dicen:

Sabed: que reunido por medio de representantes libre, pacífica y legalmente el pueblo soberano que lo habita, en esta capital de Santafé de Bogotá, con el fin de acordar la forma de gobierno que considerase más propia para hacer la felicidad pública.

Lo propio se hace en el artículo 12 del Título I: «La reunión de dos o tres funciones de los Poderes Ejecutivo, Legislativo y Judicial en una misma persona o corporación, es tiránica y contraria por lo mismo a la felicidad de los pueblos» ${ }^{58}$.

Como metodología de análisis de los fenómenos de felicidad en la vida política, recomendamos seguir el curso que va tomando la idea de felicidad en el contexto constitucional. Habría que seguir las sucesivas constituciones políticas que empiezan a surgir durante el siglo XIX. De aquí, ver cómo se vincula este material con otros mecanismos propios del siglo XIX, como puede serlo la creación sorprendente de instituciones científicas que empiezan a surgir, orientadas hacia un uso práctico de los conocimientos científicos.

Ahora bien, el campo de la felicidad va incorporando otros contenidos mediante sucesivas transformaciones de los contenidos anteriores, producto de las nuevas condiciones sociales y políticas. Nuevos conceptos empiezan a ser incorporados a la constelación felicitaria. Si se quiere, los fenómenos de felicidad empiezan a ser conceptualizados de otra manera. Sin embargo, la dialéctica del dominio intersubjetivo sigue siendo la misma, se trata de transformar los estados de insatisfacción o de malestar en estados de satisfacción o de bienestar. Pero este sería un análisis que no podríamos hacer aquí.

\section{Interpretación de los casos considerados}

¿Qué podemos interpretar de los casos fenoménicos que hemos considerado? Como corolario podríamos decir que estamos ante un dominio del campo de felicidad, los fenómenos sociales que tienen que ver «recta y formalmente con la felicidad». Esto es, aquellos fenómenos sociales que promueven desde plataformas concretas la búsqueda de la felicidad. Se trata pues, de los fenómenos que tienen que ver con los Estados, concretamente con una forma del Estado de bienestar.

En todo caso, lo que notamos con estos «casos fenoménicos» es que confirman la idea de que «los fenómenos de felicidad como bienestar se recortan en la historia de los documentos políticos constitucionales, en cuya tradición, la felicidad pública y la salud suelen ir confundidas». Pero, sobre todo, que «el fenómeno del bienestar comienza a dibujarse en el

58 Constitución de Cundinamarca (30 de marzo de 1811, y promulgada el 4 de abril de 1811). Subrayado nuestro. Fragmento tomado de Banco de la República, Constitución de Cundinamarca: su capital Santafé de Bogotá (Bogotá: Imprenta Patriótica de D. Nicolás Calvo, y Quixano, 1811), 6, https://babel.banrepcultural.org/ digital/collection/p17054coll10/id/2330.

\section{Estudios históricos}


siglo XVIII» ${ }^{59}$.

Este «fenómeno del bienestar» lograría su mayor alcance en el siglo XIX, en la Alemania de Bismark; y en el siglo xx se realiza en la Unión Soviética y en Inglaterra con el plan Beveridge hasta alcanzar la forma institucionalizada actual. Esto es, una orientación manifiesta en las políticas del desarrollo de los más diversos países hacia el bienestar y hacia la mejora de la calidad de vida (que mencionamos en el apartado anterior).

Ahora bien, el campo de felicidad que hemos «allanado» tiene como contenido primario a los sujetos corpóreos insertos en una «organización social totalizadora»: «es decir, que incluye desde su perspectiva el planeamiento prácticamente integral de la conducta humana ${ }^{60}$. El concepto de «organización totalizadora» subraya aquellos componentes que están por encima de las «voluntades individuales».

Para el contexto del Nuevo Reino de Granada, la Iglesia Católica y el Imperio ${ }^{61}$ español serían estas organizaciones totalizadoras. Mientras que, para el contexto del siglo XIX, es el Estado colombiano (en su «fase embrionaria») el que alcanza esta función. Por tanto, son estas organizaciones totalizadoras las que aparecen como las diseñadoras de planes en los cuales está precisamente las transformaciones, por medio de componentes técnicos y tecnológicos, de los estados de infelicidad en estados de felicidad. De acuerdo con las coordenadas filosóficas de las que partimos, estas transformaciones a las que se apuntaba tienen lugar en el espacio antropológico (principalmente en el eje circular y en el eje radial).

En el eje circular: aquellas transformaciones que implican un cambio de estados de malestar o de sufrimiento a uno de bienestar o de gozo. El problema de la salud médica, central a finales del siglo XVIII, tiene que ver con esto: «...puesto que su acción se dirige toda ella a transformar a los individuos enfermos - infelices - en individuos sanos - felices- ... ${ }^{62}$.

En el eje radial situamos aquellas transformaciones de los entornos que implican crear condiciones ideales para la felicidad, para vivir feliz. Se sitúan aquí todos aquellos proyectos concernientes a la agricultura, el comercio, la minería, la construcción de vías y caminos; pero también la creación de centros e instituciones para atender a los menos favorecidos. Según el profesor Bueno, «El bienestar o felicidad, en cuanto ligado al incremento de la calidad de vida, tiene una relación muy estrecha con las transformaciones del eje radial (arquitectura, decoración, ajardinamientos...)» ${ }^{63}$.

59 Bueno, El mito..., 67.

60 Gustavo Bueno, El papel de la Filosofia en el conjunto del saber (Madrid: Ciencia Nueva, 1970), 29.

61 Imperio como categoría historiográfica tradicional. «El Imperio; en su acepción diamérica, es un sistema de Estados mediante el cual un Estado se constituye como centro de control hegemónico (en materia política) sobre los restantes Estados del sistema que, por tanto, sin desaparecer enteramente como tales, se comportarán como vasallos, tributarios o, en general, subordinados al "Estado imperial”, en el sentido diamérico». Para una clasificación de la Idea de imperio ver: Gustavo Bueno, España frente a Europa (Barcelona: Alba Editorial, 1999). Sobre todo, su capítulo III: «La idea de Imperio como categoría y como Idea filosófica».

62 Bueno, El mito..., 129.

63 Bueno, El mito..., 131.

Ciencia Nueva. Revista de Historia y Política 
[Además, con igual importancia], nos ofrece la posibilidad de reconocimiento de muy diversos conceptos de felicidad o de calidad de vida, y del establecimiento de diferentes sistemas de vida feliz, resultantes del entretejimiento, más o menos estable, de diferentes valores felicitarios y de su jerarquía ${ }^{64}$.

En todo caso, los componentes del eje radial pueden intersecar con los del eje circular. Las transformaciones de las que venimos hablando no operan, como ya hemos insinuado, en el vacío. Su envoltura está dada, pues, a escala de las organizaciones totalizadoras que mencionamos.

Estas «operaciones de transformación» se mueven a través de conceptos e ideas que no logran desbordar la inmanencia del campo. Conceptos e ideas políticas, morales, económicas, psicológicas, teológicas, etc., que funcionan como el «caparazón» de los fenómenos citados. Tratados por todas las iniciativas reformistas que hemos mencionado. La idea de felicidad que opera en el Nuevo Reino de Granada es una idea funcional, al mantenimiento de la estructura administrativa del Imperio en una parte política suya como lo era el Nuevo Reino de Granada.

Nuestra tesis es que esta idea de la búsqueda de la felicidad pública surge en capas altas e ilustradas del Antiguo Régimen, y se proyecta después en círculos concéntricos a través de las organizaciones totalizadoras a otras clases sociales. Ahora bien, ¿en qué consiste esta proyección de búsqueda de la felicidad en círculos concéntricos?

Ante todo, que el origen de estas ideas son los discursos políticos, económicos y morales que los ilustrados iban elaborando y que los gobernantes iban incorporando en sus planes políticos y económicos, en una palabra, administrativos. Para la parte del Antiguo Régimen que hemos tomado como referencia (segunda mitad del siglo XVIII), esto significó, para el caso español y sus dominios al otro lado del Atlántico, que fueron sobre todo los conceptos económicos los que vincularon la felicidad con el bienestar y la prosperidad: decía Jovellanos en su discurso citado que esta felicidad consistía en un estado de abundancia y comodidades que todo buen gobierno debía procurar a sus individuos.

Una vez estos discursos se incorporaron en la estructura de los programas políticos del Imperio español, se fueron proyectando a través de las burocracias administrativas (los círculos concéntricos) hacia otras esferas sociales. Los círculos concéntricos de los que venimos hablando eran los «receptáculos» del Imperio que iban reproduciendo la estructura del centro en sus dominios coloniales. De ahí que se haya dicho, y los ejemplos que hemos considerado lo muestran, que es a través de las reformas borbónicas como esta búsqueda de la felicidad llega a Hispanoamérica ${ }^{65}$.

64 Bueno, El mito..., 131.

65 Por supuesto, habría que medir los alcances (éxitos) y las limitaciones (fracasos) de esta búsqueda de la felicidad a través de programas políticos-económicos (los planes reformadores) de la época, haciendo un análisis más exhaustivo y detallado de la estructura interna, administrativa, del Nuevo Reino de Granada. Un análisis de este tipo desborda los propósitos que nos hemos planteado en este trabajo. Pero por lo que nos muestran las fuentes y los propios ritmos de los acontecimientos, los alcances de estas reformas fueron muy limitadas.

\section{Estudios históricos}


Si quisiéramos trazar un esquema de esta estructura y de cómo se va proyectando esta búsqueda de la felicidad, tendríamos que imaginar una organización jerárquica donde la estructura burocrática-administrativa del centro (el Imperio central) se reproduce en los extremos (sus dominios americanos): a la manera como la estructura central de una célula se reproduce en sus componentes funcionales. Y luego, si ajustamos esa misma estructura a una escala menor, la de los Estados, el centro vendría a ser cada administración burocrática (gobierno) y los círculos por donde se va reproduciendo la estructura serían las instituciones (sociales, políticas, económicas, administrativas) en su interior; hablaríamos entonces de una transformación idéntica donde lo único que cambia es la escala, pero la estructura se mantiene. Es esta última situación la que nos muestra los ejemplos (de planes reformadores) que citamos para el Nuevo Reino de Granada en la segunda mitad del siglo XviII ${ }^{66}$.

Estas operaciones de transformación podrían coordinarse con las tecnologías o técnicas políticas de las que habla Michel Foucault con lo que él llama bio-política ${ }^{67}$. En este contexto, la familia sería la unidad (círculo concéntrico) mínima por donde se difunde o, mejor, se reproducen, estos contenidos de felicidad pública. Y aquí el análisis de la institución que entonces se denominaba Policía adquiere su importancia. La Policía debe entenderse, no el sentido estrictamente represivo que hoy se le da al término, sino como una unidad que envolvía a todas aquellas técnicas de transformación de los estados de infelicidad en felicidad de la población y de la «nación ${ }^{68}$.

Ahora bien, para el segundo caso, para la primera mitad del siglo xıx, la situación cambia. Ya no eran principalmente los aspectos económicos los que vinculan a la nación con la búsqueda de la felicidad, sino los políticos; sin perjuicio de que los conceptos económicos sigan manteniendo su importancia a este respecto. Lo que sucede es que ahora se incorporan en una nueva forma de entender la economía, la economía política.

Ahora es cuando adquiere mayor sentido la idea de la felicidad pública francesa proveniente de la Gran Revolución, de Robespierre. O, mejor dicho, la dialéctica que nos plantea Arendt entre la felicidad de la mayoría y la felicidad pública adquiere, en este contexto, gran importancia. Aunque las palabras de Robespierre dan la impresión de ser lo mismo, estas son distintas, pero involucradas.

66 Pero también hay otros contextos que servían como círculos concéntricos por donde las ideas ilustradas se movían, los «círculos de ilustrados científicos» del Nuevo Reino. Para un análisis detallado de la circulación de los conocimientos científicos, orientados hacia el mantenimiento de la administración del estado, ver la obra de Mauricio Nieto Olarte, Orden Natural y Orden Social: ciencia y política en el Semanario del Nuevo Reino de Granada (Bogotá: Universidad de los Andes, Facultad de Ciencias Sociales, 2007).

67 Michel Foucault, El nacimiento de la biopolítica (Buenos Aires: Fondo de Cultura Económica, 2007). Para un análisis sobre estos mecanismos, ver Jacques Donzelot, La policía de las familias (Valencia: Pre-textos, 1979)

68 En palabras de Johann Heinrich Gottlob von Justi, consejero, en sus Elementos generales de policía de 1784, del rey de Inglaterra: «Se ve pues, que el objeto de la Policía es afirmar y aumentar por la sagacidad de sus reglamentos, el poder interior del Estado; y como este poder consiste no solamente en la Republica en general, y en cada uno de los miembros que la componen, si también en las facultades y los talentos de todos los que la pertenecen; se sigue, que ella debe enteramente ocuparse de estos medios, y hacerles servir para la publica felicidad», 3. Subrayado nuestro. 
Pues cuando Robespierre se refiere a la felicidad de la mayoría está significando la voluntad de mejorar las condiciones materiales (de vida) de gran parte del pueblo; mientras que la oposición que propone Arendt con la felicidad pública es que esta última se refiere a la voluntad política de construcción de ciudadanos, garantizando la participación en la vida política, asuntos públicos ${ }^{69}$. Y si no interpretamos mal, es esa situación dialéctica la que aparece en las constituciones políticas que hemos considerado para el siglo XIX.

Como se ha dicho, la idea de la felicidad que empieza a aparecer en los textos constitucionales se va vinculando con la idea de bienestar, que busca, mediante políticas públicas, eliminar las desigualdades y estimular el progreso. El trasfondo de este viraje en la búsqueda de la felicidad nos lo muestran los proyectos constitucionales citados para Colombia, que parecen reproducir la situación europea de la época: una felicidad que debía ser el objetivo de los gobiernos.

En este contexto, la escala de medida es, como se dijo, el Estado y no el Imperio. Un Estado que empezaba a reorganizar sus estructuras políticas, liberándose del dominio español, para que el pueblo fuera feliz. Y esto mediante la destrucción de la organización social del Antiguo Régimen, variando la escala mínima política: de estamentos a ciudadanos.

En esta misma línea, se dibuja una nueva voluntad de poder que se había impuesto ante la que operaba en el periodo colonial, y que desde finales del siglo XviII se fue intensificando cada vez más como resultado de los avances en materia científica. Como consecuencia de lo anterior, aparecieron nuevos actores y nuevas disciplinas científicas que se presentaban como el «tribunal de la razón», estas establecieron otros principios de verdad. Las explicaciones se pueden buscar en la construcción de una nación moderna que empezó a adoptar cada vez más los principios y elementos conceptuales de las ciencias de la vida, la Expedición Botánica y la Comisión Corográfica, son ejemplos ilustrativos de este proceso.

La orientación de la ciencia hasta esas dos experiencias fue hacia un uso eminentemente práctico, es precisamente ese carácter el que permite ver el cambio en el orden del discurso, pues las ciencias de la vida le imprimieron coherencia y brindaban una estructura administrativa a las instituciones. Para Pedraza Gómez «fue particularmente en la introducción de las políticas de salubridad pública e higiene personal, de saneamiento y transformación del territorio, como se expandió esta forma de representación». Así, «los letrados fueron desplazados por médicos e ingenieros quienes ingresaron como agentes de producción y administración simbólica en calidad de diseñadores y ejecutores de las biopolíticas ${ }^{70}$. Ahora son los discursos científicos los que vinculaban el saber científico con el poder del Estado a través de la fundación y creación de instituciones.

Una última cosa, sobre los valores de felicidad: estos pueden agruparse o clasificarse según los contenidos de los dominios del campo de felicidad. Acaso los dos grupos más evi-

69 Arendt, ..., 112-115.

70 Zandra Pedraza Gómez, «Y el verbo se hizo carne... Pensamiento social y biopolítica en Colombia», en Pensar el siglo XIX: cultura, biopolítica y modernidad en Colombia, ed. Santiago Castro-Gómez (Pittsburgh: Instituto Internacional de Literatura Iberoamericana, 2004), 190.

\section{Estudios históricos}


dentes sean valores subjetivos y valores objetivos. Pero resulta que «la línea de frontera entre la clase de los valores subjetivos y la de los valores objetivos será siempre muy borrosa». Es decir: «los valores subjetivos (psicofisiológicos) siempre dicen referencia a algún contenido objetivo; y los valores objetivos no pueden ser separados del disfrute o goce de un sujeto ${ }^{71}$.

Aquí hemos mencionado los valores que median entre estos dos «extremos», los valores intersubjetivos. No se trata de una cuestión nuestra que se sobreañade a los fenómenos, es el resultado del material lógicamente ordenado y clasificado. La felicidad intersubjetiva, más aún, supraindividual, nos aproxima a su conónimo, «el bienestar».

Ahora bien, «La felicidad plural o el bienestar envuelve a un conjunto de valores suprasubjetivos y objetivos de la felicidad que en modo alguno pueden considerarse como una suma, o como un producto, o como una integral de valores subjetivos de la felicidad». Y esto en virtud ya no del «desborde» de la subjetividad, sino (más aún) «porque implican la contribución de tantas infelicidades de otros individuos del grupo o de la sociedad $\gg^{72}$.

Estaríamos entonces ante valores políticos de felicidad, determinados por términos como «felicidad del generoso pueblo», «felicidad de los pueblos», «felicidad pública», «felicidad del Estado», etc. (citados en la sección anterior). Lo que sucede es que a medida que los Estados van tomando su forma actual, van sustituyendo estos términos del Antiguo Régimen por el de Bienestar o, más recientemente, por calidad de vida ${ }^{73}$. En esto radica la potencia de la dialéctica entre esos dos dominios (felicidad/infelicidad) de los fenómenos de felicidad que hemos comentado.

Finalmente, la cuestión de qué grupos sociales históricamente delimitados hayan querido (y quieran) ser felices, es un problema histórico. Suscribimos una tesis fundamental del libro del profesor Bueno: «los seres humanos, organizados en sociedades políticas preestatales, permanecen en actitud neutra en relación con el Principio de felicidad». He ahí la necesidad de las investigaciones históricas para determinar cuándo y qué tipo de sociedades han querido ser felices.

\section{Referencias}

\section{Fuentes primarias}

Archivo General de la Nación. Fondo Cabildos. Sección Colonia.

Archivo General de Indias, ES.41091.AGI/23//ESTADO,57, N.28.

71 Bueno, El mito..., 339.

72 Bueno, El mito..., 340.

73 Bueno, El mito..., 341: «No estará de más insistir en que, sin embargo, y a pesar de la tendencia del español actual a utilizar el término bienestar (welfare) como conónimo de felicidad; sin embargo, la acepción del término «felicidad» en cuanto bienestar tiene una tradición acaso tan antigua (seguramente vinculada a acepciones teológicas o religiosas) como las acepciones subjetivas individualistas de la felicidad». 


\section{Fuentes primarias impresas}

Caballero y Góngora, Antonio. «Relación del estado del Nuevo Reino de Granada, que hace el arzobispo obispo ele Córdoba a su sucesor el excmo. Sr. D. Francisco Gil y Lemos. Año de 1789». En Relaciones e informes de los gobernantes de la Nueva Granada, editado por Germán Colmenares, 364-365. Bogotá: Biblioteca Banco Popular, 1989.

De Jovellanos, Gaspar Melchor. «Discurso económico sobre los medios de promover la felicidad de Asturias, dirigido a su Real Sociedad». Biblioteca Virtual del Principado de Asturias. https://bibliotecavirtual.asturias.es/i18n/consulta/registro.cmd?id=505

Gottlob von Justi, Johann Heinrich. Elementos generales de policía. Barcelona: Eulalia Piferrer viuda, 1784.

Lorenzana, Francisco Antonio. «Reglas para que los naturales de estos Reynos sean felices en lo espiritual, y temporal». En Cartas pastorales y edictos del señor D. Francisco Antonio Lorenzana y Buitron, Arzobispo de México, editado por Iglesia Católica. Arquidiócesis de México, 45-49. México: Imprenta del Superior Gobierno, del Sr. D. Joseph Antonio de Hogal, 1770. http://cdigital.dgb.uanl.mx/la/1080044716/1080044716.html.

Mendinueta, Pedro. «Relación del estado del Nuevo Reino de Granada, presentado por el Excmo. Sr. Virrey D. Pedro Mendinueta». En Germán Colmenares, Relaciones e informes de los gobernantes de la Nueva Granada, vol. II. Bogotá: Biblioteca Banco Popular, 1989.

Muratori, L. Antonio. La pública felicidad objeto de los buenos príncipes. España: Imprenta Real, 1790.

\section{Fuentes secundarias}

Alarcón, R. «Desarrollo de una escala factorial para medir la felicidad». Revista Interamericana de Psicología, 40 (2006): 99-106.

Alzate Echeverri, Adriana María. «Lugares de espanto y refugio: aspectos de la vida de algunos hospitales del Nuevo Reino de Granada, 1750-1810». En Imperios ibéricos en comarcas americanas. Estudios regionales de historia colonial brasilera y neogranadina. Bogotá: Universidad del Rosario, 2008.

Arendt, Hannah. Sobre la revolución. Buenos Aires: Alianza, 2008.

Banco de la República, Constitución de Cundinamarca: su capital Santafé de Bogotá. Bogotá: Imprenta Patriótica de D. Nicolás Calvo, y Quixano, 1811. https://babel.banrepcultural.org/digital/collection/p17054coll10/id/2330Bueno, Gustavo. El papel de la Filosofía en el conjunto del Saber. Madrid: Ciencia Nueva, 1970.

Bueno, Gustavo. El papel de la Filosofía en el conjunto del Saber. Madrid: Ciencia Nueva, 1970. Etnología y Utopía. Madrid-Gijón: Ediciones Júcar, 1987.

¿Qué es la ciencia? La respuesta de la teoría del cierre categorial. Oviedo: Pentalfa, 1995.

. El sentido de la vida. Oviedo: Pentalfa, 1996. 
Anotaciones para una historia de los fenómenos de felicidad

en Colombia: segunda mitad del siglo XVIII y principios del XIX

España frente a Europa. Barcelona: Alba Editorial, 1999.

. El mito de la felicidad. Autoayuda para desengaño de quienes buscan ser felices. Barcelona: Ediciones B, 2005.

. «Conónimos». El Catoblepas, Revista Crítica del Presente, n. ${ }^{\circ} 67$ (2007). http://www. nodulo.org/ec/2007/n067p02.htm.

Cacua, Antonio. Historia de la Educación en Colombia (Bogotá: Academia Colombiana de Historia, 1997).

Di Falco, A, «El reformismo borbónico en España y en las colonias americanas: un recorrido historiográfico», Cultura Latinoamericana, 27 (2018): 242-272.

Donzelot, Jacques. La policía de las familias. Valencia: Pre-textos, 1979.

Eissa-Barroso, F. y A. Vásquez. Early Bourbon Spanish America. Politics and Society in a Forgotten Era (1700-1759). Bostón: Brill Academic Publisher, 2013.

Foucault, Michel. El nacimiento de la biopolítica. Buenos Aires: Fondo de Cultura Económica, 2007.

Garrido, Margarita. Reclamos y representaciones. Variaciones sobre la política en el Nuevo Reino de Granada 1770-1815. Bogotá, Banco de la República, 1993.

Gilbert, Daniel. Tropezar con la felicidad. Barcelona: Ediciones Destino S.A, 2006.

Guimón, Pablo. «El reino que quiso medir la felicidad». El País, 29 de noviembre de 2009. Acceso el 30 de noviembre de 2021. https://elpais.com/diario/2009/11/29/ eps/1259479614 850215.html

Helliwell, John F., Richard Layard, Jeffrey Sachs y Jan-Emmanuel De Neve, eds. World Happiness Report 2020. New York: Sustainable Development Solutions Network, 2020.

Houghton, Teresa, Comp. La Ilustración en Colombia. Bogotá: Universidad Santo Tomás, Biblioteca Colombiana de Filosofía, 1990.

Howell, R., Kern, M., y Lyubomirsky, S. «Health benefits: meta-analytically determining the impact of well-being on objective health outcomes», Health Psychology Review, 1 (2007): 83-136.

Jaramillo, J. «El proceso de la educación en el virreinato», Nueva Historia de Colombia. Bogotá: Editorial Planeta, 1989. . «La administración colonial», Nueva Historia de Colombia. Editorial Planeta, 1989.

Kahneman, Daniel. «Experienced Utility and Objective Happiness: A Moment-Based Approach». En Choices, Values, and Frames, editado por Daniel Kahneman y Amos Tversky. Nueva York: Cambridge, 2000.

Marías, Julián. La felicidad humana. Madrid: Alianza Editorial, 1989.

Marti, Marc. «El concepto de felicidad en el discurso económico de la Ilustración», Cuadernos Dieciochistas, 13 (2013): 251-270. 
McMahon, Darrin. Una historia de la felicidad. Madrid: Taurus, 2006.

Moyano, Emilio. «Trends and Challenges for the Research of Happiness in Latin America». En Handbook of Happiness Research in Latin America, editado por Mario Rojas. Dordrecht: Springer, 2016.

Navarro García, Luis. «La crisis del reformismo borbónico bajo Carlos IV». Temas Americanistas, 13 (1997): 1-22.

Nieto Olarte, Mauricio. Orden Natural y Orden Social: ciencia y política en el Semanario del Nuevo Reino de Granada. Bogotá: Universidad de los Andes, Facultad de Ciencias Sociales, 2007.

Ocampo López, Javier y Consuelo Soler Lizarazo. Reformismo en la educación colombiana. Historia de las políticas educativas 1770-1840. Bogotá: Instituto para la Investigación Educativa y el Desarrollo Pedagógico (IDEP), 2012.

Ortega Ricaurte, Enrique. Cabildos de Santafé de Bogotá: cabeza Nuevo Reino de Granada, 1538-1810. Bogotá: Imprenta Nacional de Publicaciones, 1957.

Cundinamarca. Constitución de Cundinamarca: su capital Santafé de Bogotá. Bogotá: Imprenta Patriótica de D. Nicolás Calvo, y Quixano, 1811.

Pearce, Adrian. J. The origins of Bourbon reform in Spanish South America, 1700-1763. New York: Palgrave McMillan, 2010.

Pedraza Gómez, Zandra. «Y el verbo se hizo carne... Pensamiento social y biopolítica en Colombia». En Pensar el siglo XIX: cultura, biopolítica y modernidad en Colombia, ed. Santiago Castro-Gómez. Pittsburgh: Instituto Internacional de Literatura Iberoamericana, 2004.

Robinson, David James. Francisco Silvestre. Relación de la provincia de Antioquia. Medellín: Secretaría de Educación y Cultura de Antioquia, 1988.

Robledo, Emilio. Bosquejo biográfico del señor oidor Juan Antonio Mon y Velarde. Visitador de Antioquia, 1785-1788, vol. I y II. Bogotá: Banco de la República, 1954.

Silva, Renán. Los ilustrados de Nueva Granada 1760-1808. Medellín: Banco de la República, 2002.

Soubeyroux, Jacques. «El discurso de la Ilustración sobre la pobreza. Análisis de una formación discursiva». Nueva Revista de Filología Hispánica 33, n. ${ }^{\circ} 1$ (1984): 115-132.

Vargas Lesmes, Julián. La sociedad de Santafé colonial. Bogotá: CINEP, 1990.

Villamizar Duarte, C. Vladimir. La felicidad del Nuevo Reino de Granada: el lenguaje patriótico en Santafé (1791-1797). Bogotá: Universidad Externado de Colombia, 2012. 